\title{
CHEST PAIN IN AN ELITE MASTER ULTRA-MARATHON RUNNER: A CASE REPORT WITH A FOLLOW-UP ON HIS SUBSEQUENT ATHLETIC ACTIVITY
}

\author{
EWA SADOWSKA-KRĘPA ${ }^{1}$, BARBARA KŁAPCIŃSKA ${ }^{1}$, DAGMARA GERASIMUK ${ }^{2}$, ADAM RZETECKI ${ }^{1}$, \\ ZBIGNIEW WAŚKIEWICZ ${ }^{1,3}$, ZBIGNIEW GĄSIOR ${ }^{4}$, ALEKSANDRA ŻEBROWSKA ${ }^{1}$, THOMAS ROSEMANN ${ }^{5}$, \\ PANTELIS T. NIKOLAIDIS ${ }^{6}$, and BEAT KNECHTLE ${ }^{5,7}$
}

${ }^{1}$ Jerzy Kukuczka Academy of Physical Education, Katowice, Poland

Institute of Sport Sciences

${ }^{2}$ Jerzy Kukuczka Academy of Physical Education, Katowice, Poland

Department of Sports Training

${ }^{3}$ Sechenov University, Moscow, Russia

Department of Sports Medicine and Medical Rehabilitation

${ }^{4}$ Medical University of Silesia, Katowice, Poland

Department of Cardiology, School of Health Science

${ }^{5}$ University of Zurich, Zurich, Switzerland

Institute of Primary Care

${ }^{6}$ Exercise Physiology Laboratory, Nikaia, Greece

${ }^{7}$ Medbase St. Gallen Am Vadianplatz, St. Gallen, Switzerland

\begin{abstract}
Ultra-marathon running has enjoyed increasing popularity, with the number of master ultra-marathon runners growing annually. This study presents a case of a 51-year-old highly experienced long-distance runner (body mass: $65.1 \mathrm{~kg}$, body height: $168 \mathrm{~cm}$ ), who took part in a 48-h ultra-marathon race held in 2010, but dropped out of the competition due to acute cardiac problems manifested after $16 \mathrm{~h}$ of running and having completed a distance of $129 \mathrm{~km}$. Two weeks following the race, intense cardiac examination was performed to explain the drop-out due to chest pain. A 12-lead electrocardiogram, a 2D transthoracic echocardiography in 3 apical projections of the left ventricle, a computed tomography of the chest, an invasive coronary angiography and a maximal oxygen uptake $\left(\mathrm{VO}_{2 \max }\right)$ test were performed. The 12-lead ECG revealed a negative T wave in III and aVF without morphological abnormalities. The echocardiographic examinations presented a normal size and function of the heart chambers, and a normal valvar structure and function (only trivial mitral and tricuspid regurgitation was observed). The invasive coronary arteriography - due to an increased calcium score in the CT scan - showed only a non-significant systolic dynamic narrowing in the eighth segment of the left anterior descending artery due to a muscle bridge. The physical performance characteristics of the athlete and a follow-up history of his athletic activity showed that the cardiac problems he had experienced during the ultra-marathon race did not prevent him from being active in sport. Int J Occup Med Environ Health. 2020;33(4):523-34
\end{abstract}

Key words:

running, drop-out, health outcomes, metabolic changes, ultra-marathon race, physical ability

Funding: this study was supported by the Jerzy Kukuczka Academy of Physical Education (project No. 2008-10 entitled "Metabolic changes in human body and experimental animals induced by physical exercise and/or dietary supplementation,” project manager: Prof. Barbara Kłapcińska).

Received: September 8, 2019. Accepted: March 19, 2020.

Corresponding author: Beat Knechtle, Medbase St. Gallen Am Vadianplatz, Vadianstrasse 26, 9001 St. Gallen, Switzerland (e-mail: beat.knechtle@hispeed.ch). 


\section{INTRODUCTION}

Ultra-marathon running, in which mainly master athletes compete, has enjoyed increasing popularity [1]. Ultramarathon races are mainly held as distance-limited [2] or time-limited [1] races. There is much evidence on the beneficial effects of regular physical activity on the cardiovascular system [3]. However, participation in a prolonged strenuous exercise such as an ultra-marathon race leads to severe metabolic stress [4], which may lead to a substantially increased health risk evidenced by an altered cardiac function and marked increases in blood markers of skeletal muscle and cardiac muscle damage [5], or even to a sudden cardiac death [6]. Most studies on physiological and metabolic effects of ultra-distance running have been conducted on successful finishers, while the metabolic profile of non-finishers is described only in a few reports [7]. In fact, 48-h ultra-marathon races are rarely held [1] and very little scientific data exists for this kind of ultra-marathon running, with 1 case report investigating pre-race preparation [8], 1 case report pacing during the race [9], and a field study investigating metabolic changes during and after the race [10].

To the best of the authors' knowledge, no case report has ever investigated the evaluation of acute chest pain during a 48-h ultra-marathon race in a master runner. In the present case study, the authors describe a highly experienced ultra-marathon runner who had to stop after $16 \mathrm{~h}$ of running, during a 48-h ultra-marathon race held in 2010, due to acute chest pain. The primary intention was to examine metabolic changes during and after the race. However, the athlete was then also examined with regard to the reasons for the acute chest pain. Extensive cardiac examination with a 12-lead electrocardiogram (ECG), a 2D transthoracic echocardiography in 3 apical projections of the left ventricle, a computed tomography (CT) of the chest, an invasive coronary angiography, and a maximal oxygen uptake $\left(\mathrm{VO}_{2 \max }\right)$ test were performed after the race. With a longterm follow-up history of his later sports achievements af- ter this drop-out (i.e., 2010-2019), the authors were able to present important and new aspects of the severity of longterm health problems in ultra-marathon runners.

\section{CASE PRESENTATION}

\section{Participant and ethical approval}

In June 2010, a 51-year-old highly experienced long-distance runner (body mass: $65.1 \mathrm{~kg}$, body height: $168 \mathrm{~cm}$ ) took part in a 48-h ultra-marathon race organized by the Jerzy Kukuczka Academy of Physical Education in Katowice. This was his 55th start in a running event on a track $>42.195 \mathrm{~km}$, during which he planned to improve his life record $(370.381 \mathrm{~km})$ achieved in 2000 during the Brno 48-h indoor international endurance race. The study protocol conformed to the ethical guidelines of the World Medical Association's Declaration of Helsinki and was approved by the Institutional Ethics Committee at the Jerzy Kukuczka Academy of Physical Education (decision No. 1/2009). Consent to the processing of personal data was provided by all participants.

\section{Characteristics of the race,}

study protocol and race results

The 48-h ultra-marathon race was held on a 3000-m oval walking trail situated on the flat outskirts of Katowice. The distance covered was estimated through automated counting of passages through an electronic gate set up at the trail. All competitors were allowed free (unrecorded) access to food (e.g., sandwiches, cookies, bananas, carbohydrate energy bars) and liquids (e.g., water, sport beverages, soft drinks and broth), and a small amount ( $<100 \mathrm{ml})$ of coffee every $8 \mathrm{~h}$. Environmental conditions at the start of the race (12 a.m.) and after $12 \mathrm{~h}$ of running were good, with a temperature of $22^{\circ} \mathrm{C}$ and $15^{\circ} \mathrm{C}$, and relative humidity of $53 \%$ and $100 \%$, respectively. Samples of venous and capillary blood were collected $3 \mathrm{~h}$ before the start of the competition, after $12 \mathrm{~h}$ of running and, in this case, consequent to a drop-out of the race due to acute chest 
pain occurring after $16 \mathrm{~h}$ of running, also after 12, 36 and $60 \mathrm{~h}$ of passive recovery.

\section{Laboratory analyses}

All blood samples collected during the event were immediately transported to the internal medicine clinical laboratory for performing biochemical analyses. Measurements of blood gases, electrolytes, lactate and glucose in fingertip capillary blood were performed using the GEM Premier 3000 with Intelligent Quality Management (Instrumentation Laboratory, Bedford, USA). Blood morphology was assessed in venous blood samples (anti-coagulated with ethylenediaminetetraacetic acid) using an Automated Hematology Analyzer XS-1000i ${ }^{\mathrm{TM}}$ (Sysmex, Kobe, Japan). Serum ferritin was measured using an Abbott Architect i2000 SR analyzer, serum iron (Fe) using Olympus AU400 (Olympus, Tokyo, Japan) and plasma soluble transferrin receptor (sTfR) using a BN ProSpec nephelometer (Siemens Healthcare Diagnostics, Erlangen, Germany). Serum activities of creatine kinase (CK), lactate dehydrogenase (LDH), aspartate aminotransferase (AST), alanine aminotransferase (ALT) and $\gamma$-glutamyl transferase $(\gamma \mathrm{GT})$, as well as serum concentrations of total cholesterol (TC), high-density lipoprotein cholesterol (HDL-C), lowdensity lipoprotein cholesterol (LDL-C), and triglycerides (TG), were measured using the clinical chemistry analyzer Synchron CX 9 Pro (Beckman Coulter, Krefeld, Germany). The intra-assay coefficients of variation (CV) for these assays were $5.8 \%, 6.70 \%, 5.30 \%, 5.60 \%$ and $3.50 \%, 6.10 \%$, $4.50 \%$, respectively.

High-sensitivity C-reactive protein (hsCRP) was assessed in serum by a turbidimetric immunoassay using a Dade-Behring (Dade Berhring Marburg GmbH, Marburg, Germany) kit (intra assay CV: $3.45 \%$ ). Serum free fatty acids (FFA) and glycerol contents were assessed using commercially available manual test kits NEFA and glycerol (GLY) (CV: 2.7 and 1.34, respectively) from Randox Laboratories Ltd., Crumlin, UK. To evaluate the risk of the coronary artery disease $(\mathrm{CAD})$ in the competitor, the atherogenic index of plasma $\left[\right.$ AIP $=\log _{10}(\mathrm{TG} / \mathrm{HDL}-\mathrm{C})$ with TG and HDL-C expressed in molar concentrations] [11] was calculated.

\section{Cardiac examinations after the race}

Two weeks following the race, spent first on passive and then on active recovery aimed to regain his physical and psychological well-being, the runner presented to the Cardiology Unit of the Medical University of Silesia for a follow-up consultation. During his 4-day stay in the hospital ward, targeted at finding the cause of the stenocardial symptoms that occurred during the ultra-marathon race after $16 \mathrm{~h}$ of continuous running, he was subjected to diagnostic procedures. A CT of the chest was performed to evaluate cardiac risk profiles and cardiac procedures (calcium scoring) (Toshiba Medical Systems Corporation, Otawara, Japan). A 12-lead ECG was performed to analyze heart rhythm and the ST-segment abnormalities. A resting 2D transthoracic echocardiography (TTE) in 3 apical projections of the left ventricle (LV) was performed using the Vivid system (GE Vingmed Ultrasound AS, Horten, Norway). Following the guidelines of the American Society of Echocardiography, 4-, 2-, and 3-chamber examinations were performed. The left ventricular end-diastolic diameter (LVEDd), the left ventricular end-systolic diameter (LVESd) and the right ventricular diastolic dimension (RVDd), were acquired using the Simpson method with the assumption that the chambers are spherical and constitute the arithmetic mean of the indicated volumes in both the 4- and 2-chamber projections. The left ventricular ejection fraction (LVEF) constituted the ratio of the stroke volume and the left ventricular end-diastolic volume (LVEDV), and was calculated as the arithmetic mean of 3 subsequent measurements.

The left ventricular mass (LVM) and the left ventricular muscle mass index (LVMI) were calculated. The LVMI was calculated relative to the body surface area (BSA) and was expressed as LVM/BSA. To assess cardiac hypertrophy, LVMI values $>134 \mathrm{~g} / \mathrm{m}^{2}$ were adopted, as recom- 
Table 1. Characteristics and 48-h race performance of the study participant during an ultra-marathon race in Katowice, Poland, June 20, 2010

\begin{tabular}{|c|c|}
\hline Variable & Value \\
\hline Running history [years] & 20 \\
\hline \multicolumn{2}{|l|}{ Races completed before June 2010 [n] } \\
\hline ultra-marathons & 55 \\
\hline marathons & 150 \\
\hline \multicolumn{2}{|l|}{ Training } \\
\hline \multicolumn{2}{|l|}{ range I } \\
\hline distance $[\mathrm{km}]$ & $20-40$ \\
\hline average running pace $[\mathrm{min} / \mathrm{km}]$ & $4: 30$ \\
\hline \multicolumn{2}{|l|}{ range II } \\
\hline distance $[\mathrm{km}]$ & $8-15$ \\
\hline average running pace $[\mathrm{min} / \mathrm{km}]$ & $3: 45-4: 00$ \\
\hline \multicolumn{2}{|l|}{ range III } \\
\hline distance $[\mathrm{km}]$ & $0.4-3$ \\
\hline average running pace $[\mathrm{min} / \mathrm{km}]$ & $5: 00$ \\
\hline \multicolumn{2}{|l|}{ Body weight $[\mathrm{kg}]$} \\
\hline pre-race & 65.8 \\
\hline post-race & 65.4 \\
\hline \multicolumn{2}{|l|}{ Distance $[\mathrm{km}]$} \\
\hline $6 \mathrm{~h}$ of running & 63.0 \\
\hline $12 \mathrm{~h}$ of running & 112.5 \\
\hline $16 \mathrm{~h}$ of running & 129.0 \\
\hline \multicolumn{2}{|l|}{ Running velocity $[\mathrm{km} / \mathrm{h}]$} \\
\hline at a marathon distance $(42.195 \mathrm{~km})$ & 10.5 \\
\hline first $6 \mathrm{~h}$ of running & 10.3 \\
\hline $12 \mathrm{~h}$ of running & 9.40 \\
\hline $16 \mathrm{~h}$ of running & 7.91 \\
\hline
\end{tabular}

mended by Levy et al. [12]. Pulsed-wave Doppler imaging was used to measure the LV outflow. The mitral inflow Eand $\mathrm{A}$-wave velocities were measured, and the $\mathrm{E} / \mathrm{A}$ ratio was calculated along with coronary angiography.

\section{Testing of exercise performance after the race}

Three weeks following the race (i.e., 2 months before returning to ultra-marathon running), the runner presented to the Human Performance Laboratory of the Academy of Physical Education for physical performance testing to assess his anaerobic threshold (AnT) based on the ventilatory threshold (VT) [13] and peak oxygen uptake $\left(\mathrm{VO}_{2 \max }\right)$ using a stationary breath-by-breath metabolic unit (MetaLyzer 3BR2, Cortex Biophysik GmbH, Leipzig, Germany). The test was performed on a model LE 200 treadmill (H/P/Cosmos Sports \& Medical GmbH, Nussdorf, Germany), beginning at $6 \mathrm{~km} / \mathrm{h}$ and $0^{\circ}$ inclination, following which the treadmill speed was increased by $2 \mathrm{~km} / \mathrm{h}$ every 3 min until reaching $14 \mathrm{~km} / \mathrm{h}$, then kept steady but combined with a gradual increase in treadmill grade by $2.5 \%$ every $3 \mathrm{~min}$, in order to ensure similar workload increments on the subsequent steps of the test continued until volitional fatigue [14]. Criteria for termination of $\mathrm{VO}_{2 \max }$ were voluntary exhaustion, a respiratory ratio $\geq 1.15(\mathrm{RER} \geq 1.15)$ and a $\mathrm{VO}_{2}$ plateau [15].

\section{RESULTS}

The study subject's characteristics and his 48-h race performance measures are presented in Tables 1 and 2 . The ECG revealed a negative T wave in III and aVF without ST segment depression or morphological abnormalities. Echocardiographic examinations presented normalsized heart chambers, their function and a normal valvar structure and function (only trivial mitral and tricuspid regurgitation was observed). A low resting heart rate (HR) and diastolic blood pressure were observed. The LV EF and the LV diastolic function, characterized by the peak early diastolic filling to peak late diastolic filling (E/A) ratio, did not differ compared to references ranges. Because of the calcium score (193 Agatston units) in the CT of the heart - indicating a potential coronary artery disease the authors performed an invasive coronary angiography. Only systolic dynamic narrowing in the eighth segment of the left anterior descending artery due to muscle bridging was noticed. Results of echocardiographic variables, resting HR, SBP/DBP, mitral inflow E- and A-wave velocities or the $\mathrm{E} / \mathrm{A}$ ratio are presented in Table 3. 
Table 2. Physical performance characteristics of the study participant during an ultra-marathon race in Katowice, Poland, June 20, 2010

\begin{tabular}{|c|c|}
\hline Parameter & Value \\
\hline \multicolumn{2}{|l|}{ Body parameters } \\
\hline height $[\mathrm{cm}]$ & 168 \\
\hline $\operatorname{mass}[\mathrm{kg}]$ & 65.1 \\
\hline \multicolumn{2}{|l|}{ fat } \\
\hline in $\mathrm{kg}$ & 6.6 \\
\hline in $\%$ & 10.2 \\
\hline $\mathrm{BMI}\left[\mathrm{kg} / \mathrm{m}^{2}\right]$ & 23.1 \\
\hline \multicolumn{2}{|l|}{$\begin{array}{l}\text { Weekly covered distance over the last } 2 \text { weeks } \\
\text { before the race }[\mathrm{km}]\end{array}$} \\
\hline first week & 114 \\
\hline second week & 84 \\
\hline $\mathrm{VO}_{2 \max }[\mathrm{ml} / \mathrm{kg} / \mathrm{min}]$ & 60 \\
\hline Individual anaerobic threshold $[\mathrm{ml} / \mathrm{kg} / \mathrm{min}]$ & 48 \\
\hline $\mathrm{LT}\left[\% \mathrm{VO}_{2 \max }\right]$ & 78 \\
\hline Velocity at LT $[\mathrm{km} / \mathrm{h}]$ & 12 \\
\hline \multicolumn{2}{|l|}{ Workload [W/kg] } \\
\hline at LT & 3.1 \\
\hline maximal & 4.7 \\
\hline $\mathrm{VE}[1 / \mathrm{min}]$ & 121 \\
\hline \multicolumn{2}{|l|}{ Heart rate $[\mathrm{bpm}]$} \\
\hline peak & 180 \\
\hline at LT & 155 \\
\hline Peak serum lactate $[\mathrm{mmol} / 1]$ & 6.48 \\
\hline
\end{tabular}

BMI - body mass index; LT - lactate threshold; VE - minute ventilation; $\mathrm{VO}_{2 \max }$ - maximal oxygen uptake.

The selected biochemical variables were first determined to evaluate the influence of ultra-marathon running on the metabolic and physiological strain. The effects of ultra-endurance running on blood acid-base balance, the concentration of electrolytes, the blood glucose levels, the iron status, morphology, and the lipid profile are presented in Tables 4. Data concerning the ultra-marathon runner were compared with reference values. Laboratory findings were normal, in particular, blood electrolytes (i.e., $\mathrm{Ca}, \mathrm{Na}, \mathrm{K})$, lactate, glucose, and the iron status did not
Table 3. Echocardiographic evaluation of the study participant during an ultra-marathon race in Katowice, Poland, June 20, 2010

\begin{tabular}{lc}
\hline \multicolumn{1}{c}{ Parameter } & Value \\
\hline Left ventricular mass [g] & 148 \\
Left ventricular muscle mass index $\left[\mathrm{g} / \mathrm{m}^{2}\right]$ & 86 \\
Interventricular septum [mm] & 9 \\
Posterior wall thickness [mm] & 9 \\
Relative wall thickness [\%] & 38 \\
Left ventricular end-diastolic diameter [mm] & 48 \\
Left ventricular end-systolic diameter [mm] & 29 \\
Left ventricular ejection fraction [\%] & 64 \\
Right ventricular diastolic dimensions [mm] & 28 \\
Resting heart rate [bpm] & 57 \\
Blood pressure [mm Hg] & \\
systolic & 128 \\
diastolic & 80 \\
E [m/s] & 0.6 \\
A [m/s] & 0.9 \\
E/A & 0.7 \\
\hline
\end{tabular}

A - peak velocity flow in the late diastole caused by atrial contraction (the A wave); E- peak velocity blood flow from the left ventricular relaxation in the early diastole (the $\mathrm{E}$ wave); $\mathrm{E} / \mathrm{A}$ - the ratio of the mitral inflow E- and A-waves.

differ significantly from the corresponding normal ranges. A tendency to lower $\mathrm{K}^{+}$levels after $12 \mathrm{~h}$ of recovery, compared to pre-race values, was observed. The blood morphology remained normal. However, the serum activities of CK and LDH were slightly higher. The pre-race level of LDL-C (3.89 $\mathrm{mmol} / \mathrm{l})$ was higher compared to the reference value $(3.5 \mathrm{mmol} / \mathrm{l})$.

Analyses of the selected cardiac markers were performed regarding the risk of cardiac abnormalities. The blood creatinine, high-sensitive cardiac troponin T (hsTnT $<0.014 \mu \mathrm{g} /$ ), and CK myocardial band (CK-MB) were within the normal range (17 U/1). Contrary to expectations, the authors found no significant differences in the expression of these injuryrelated markers in the ultra-marathon runner, either at 12-h distance or in response to post-race recovery. 
Table 4. Changes in the parameters recorded in the study participant during an ultra-marathon race in Katowice, Poland, June 20, 2010

\begin{tabular}{|c|c|c|c|c|c|c|}
\hline \multirow[b]{2}{*}{ Parameter } & \multicolumn{6}{|c|}{ Parameter value } \\
\hline & normal ranges & pre-race & $\begin{array}{l}\text { after } 12 \mathrm{~h} \\
\text { of running }\end{array}$ & $\begin{array}{l}\text { after } 12 \mathrm{~h} \\
\text { of recovery }\end{array}$ & $\begin{array}{l}\text { after } 36 \mathrm{~h} \\
\text { of recovery }\end{array}$ & $\begin{array}{l}\text { after } 60 \mathrm{~h} \\
\text { of recovery }\end{array}$ \\
\hline $\mathrm{pH}$ & $7.35-7.45$ & 7.40 & 7.50 & 7.47 & 7.43 & 7.44 \\
\hline $\mathrm{pCO}_{2}[\mathrm{~mm} \mathrm{Hg}]$ & $35-45$ & 44 & 35 & 39 & 42 & 41 \\
\hline $\mathrm{pO}_{2}[\mathrm{~mm} \mathrm{Hg}]$ & $75-100$ & 69 & 77 & 77 & 71 & 71 \\
\hline Standard bicarbonate $\mathrm{HCO}_{3}^{-}[\mathrm{mmol} / \mathrm{l}]$ & $22-26$ & 27.3 & 27.3 & 28.4 & 27.9 & 27.8 \\
\hline $\mathrm{Ca}^{2+}[\mathrm{mmol} / \mathrm{l}]$ & $1.13-1.30$ & 1.23 & 1.21 & 1.20 & 1.23 & 1.21 \\
\hline $\mathrm{Na}^{+}[\mathrm{mmol} / \mathrm{l}]$ & $135-145$ & 143 & 142 & 140 & 141 & 139 \\
\hline $\mathrm{K}^{+}[\mathrm{mmol} / \mathrm{l}]$ & $3.5-5.1$ & 4.7 & 4.8 & 4.4 & 4.9 & 5.5 \\
\hline Lactate $[\mathrm{mmol} / \mathrm{l}]$ & $0.5-2.4$ & 2.4 & 2.4 & 1.9 & 1.9 & 2.7 \\
\hline Glucose $[\mathrm{mmol} / \mathrm{l}]$ & $3.9-5.8$ & 4.3 & 5.9 & 4.4 & 5.8 & 6.4 \\
\hline sTfR [mg/l] & $0.83-1.76$ & 1.05 & 1.3 & 0.82 & 0.84 & 0.82 \\
\hline Ferritin $[\mu \mathrm{g} / 1]$ & $22-275$ & 48.2 & 65.7 & - & - & 87.9 \\
\hline $\mathrm{Fe}[\mu \mathrm{mol} / \mathrm{l}]$ & $10-30.8$ & 25.9 & 7.1 & 27.4 & 26.7 & 21.0 \\
\hline sTfR/ $/ \log _{10}$ ferritin index & $0.63-1.8$ & 0.624 & 0.715 & - & - & 0.422 \\
\hline $\mathrm{Hb}[\mathrm{g} / \mathrm{dl}]$ & $11.2-15.8$ & 14.9 & 15.0 & 12.9 & 13.5 & 13.1 \\
\hline $\mathrm{RBC}\left[\times 10^{6} / \mu \mathrm{l}\right]$ & $4.0-5.8$ & 4.78 & 4.81 & 4.11 & 4.35 & 4.18 \\
\hline HCT [\%] & $35-45$ & 43 & 42 & 37 & 39 & 38 \\
\hline $\mathrm{WBC}\left[10^{9} / 1\right]$ & $4-10$ & 6.5 & 15.7 & 11.0 & 6.5 & 5.6 \\
\hline Neutrophils [\%] & $40-80$ & 62.2 & 83.9 & 65.5 & 68.2 & 67.8 \\
\hline Lymphocytes [\%] & $20-40$ & 27.4 & 7.4 & 23.3 & 22.9 & 21.7 \\
\hline PLT $\left[\times 10^{3} / \mu 1\right]$ & $130-400$ & 226 & 280 & 221 & 192 & 230 \\
\hline hsCRP [mg/l] & $\leq 5$ & 0.16 & 2.0 & 23.3 & 23.0 & 12.1 \\
\hline AST [U/l] & $5-40$ & 30 & 55 & 75 & 88 & 69 \\
\hline ALT [U/l] & $5-40$ & 31 & 35 & 38 & 44 & 50 \\
\hline GGT [U/l] & $18-100$ & 23 & - & 21 & 20 & 23 \\
\hline $\mathrm{CK}[\mathrm{U} / \mathrm{l}]$ & $55-370$ & 181 & 1433 & 2345 & 1921 & 959 \\
\hline $\mathrm{LDH}[\mathrm{U} / \mathrm{l}]$ & $120-230$ & 185 & 284 & 249 & 261 & 247 \\
\hline $\mathrm{TC}[\mathrm{mmol} / \mathrm{l}]$ & $<5.2$ & 6.0 & - & 4.8 & 5.2 & - \\
\hline LDL-C [mmol/l] & $<3.5$ & 3.89 & - & 3.12 & 3.28 & - \\
\hline HDL-C [mmol/l] & $0.7-1.7$ & 1.5 & - & 1.5 & 1.6 & - \\
\hline $\mathrm{TG}[\mathrm{mmol} / \mathrm{l}]$ & $0.4-1.8$ & 1.5 & - & 0.5 & 0.8 & - \\
\hline Fatty acids [mmol/l] & $0.1-0.9$ & 0.402 & 2.977 & 0.447 & 0.402 & 0.432 \\
\hline Glycerol $[\mu \mathrm{mol} / 1]$ & 28-108 & 31.5 & 575.7 & 29.0 & 59.2 & 27.7 \\
\hline AIP & - & 0.0 & - & -0.477 & -0.301 & - \\
\hline
\end{tabular}

AIP - atherogenic index of plasma; ALT - alanine aminotransferase; AST - aspartate aminotransferase; $\mathrm{Ca}^{2+}$ - calcium; $\mathrm{CK}$ - creatine kinase; $\mathrm{Fe}$ - iron; GGT - $\gamma$-glutamyl transferase; $\mathrm{Hb}$ - hemoglobin; $\mathrm{HCO}_{3}^{-}$- standard bicarbonate; HCT - hematocrit; HDL-C - high density lipoprotein cholesterol; hsCRP - high sensitivity C-reactive protein; $\mathrm{K}^{+}$- potassium; LDH - lactate dehydrogenase; LDL-C - low density lipoprotein cholesterol; $\mathrm{Na}^{+}$- sodium; $\mathrm{pCO}_{2}$ - partial pressure of carbon dioxide; $\mathrm{pH}$ - power of hydrogen; $\mathrm{PLT}$ - platelets; $\mathrm{pO}_{2}$ - partial pressure of oxygen; $\mathrm{RBC}$ - red blood cells; sTfR - soluble transferrin receptor; TC - total cholesterol; TG - triglycerides; WBC - white blood cells. 


\section{DISCUSSION}

In this case report, the authors describe different metabolic and cardiac characteristics of an ultra-marathon runner who had to stop during a 48-h ultra-marathon race due to acute chest pain. The most important aspect in this case study is the discovery that no severe cardiac problems were detected using extensive and invasive cardiac examinations. According to the echocardiographic examination, the final diagnosis suggested that the cardiac incident was due to ischemic heart disease. The echocardiographic examinations of the LV and RV dimensions performed after completion of the race showed normal values (Table 3).

However, further findings were a mild mitral regurgitation and a tricuspid regurgitation, as well as a mixed hyperlipidemia. In the interview, stenocardial ailments during intense physical exertion appeared, as well as negative T waves in III and aVF in the ECG. In the echocardiography, no segmental or global shrinkage disorders could be detected. In the CT of the heart, a calcium score of $193 \mathrm{AU}$ was measured, indicating the moderate risk of coronary events in the future. In the coronary angiography, a muscle bridge appeared in the course of the anterior descending artery (the eighth left anterior descending artery segment) narrowing the artery (40-50\%) uncritically during contraction. Based on the results of examinations and tests, the cardiologists advised the runner against participating in athletic events.

The increase in the popularity of ultra-marathon running participation contributes to the increase in the number of reports on cardiac dysfunction in elite as well as amateur athletes. Prolonged exertion might have serious pathophysiological consequences, including pathological heart hypertrophy, cardiovascular complications and a higher risk of exercise-induced arrhythmogenic sudden cardiac death [16]. Epidemiological studies have confirmed an association between very intense endurance training and a 3-8-fold increased risk of atrial fibrillation in individuals without coexisting cardiovascular risk factors. It has been hypothesized that training-induced bradycardia, atrial dilatation and, possibly, atrial premature beats (Coumel's triangle) are the main arrhythmogenic contributors to exercise-induced atrial fibrillation [17].

Findings have suggested an increased risk of atrial fibrosis, possibly due to cumulative minor structural damage after each exercise bout. These adverse cardiovascular consequences may be associated with abnormal release of cardiac biomarkers (e.g., cardiac troponin T [cTnT], CK-MB, myoglobin, and N-terminal prohormone of brain natriuretic peptide [NTproBNP]) [10]. The main cardiac biomarkers have different times of reaching maximal concentrations after a run, compared to pre-race values. Therefore, in this case study, the authors did not analyze the dynamic of biomarkers secretion during the ultramarathon race, but only after the time point of the chest pain.

\section{Performance characteristics of the runner}

There is no doubt that the runner was a highly specialized long-distance runner with $>20$ years of regular running experience, who has already participated in 55 ultramarathon races. In the athlete's medical history, there was no hint of cardiovascular diseases. Before the incident, his typical peak training mileage was $120-160 \mathrm{~km} /$ week, while within 2 weeks preceding the race (the tapering period), the training load was lowered to 114 and $84 \mathrm{~km} /$ week, separated by a 2-day recovery. The runner is the World Championships bronze medalist in the 48-h race with the Polish record of $370 \mathrm{~km} 381 \mathrm{~m}$, and a silver (2008) and bronze (2009) medalist at the Polish Championships in the 24-h race. The high level of his running performance is reflected by his high $\mathrm{VO}_{2 \max }$ and lactate threshold expressed as $\% \mathrm{VO}_{2 \max }$ (Table 4), as well as by his capacity to maintain a stable running velocity $(10.5 \mathrm{~km} / \mathrm{h})$ over the traditional marathon distance covered in $3: 58 \mathrm{~h}$, only slightly reduced $(10.3 \mathrm{~km} / \mathrm{h})$ over the whole 12 -h period (Table 1$)$, and also by the distance covered ( 63.0 and $112.5 \mathrm{~km}$ ) and the run- 
ning speed (10.5 and $9.40 \mathrm{~km} / \mathrm{h}$ ) during the first 6 and $12 \mathrm{~h}$ of the race (Table 1).

It is worth noting that the above mentioned data are better than those reported previously $[10,18]$ in amateur runners participating in 24-h or 48-h ultra-marathon races held on the same site. In addition, the values of $\mathrm{VO}_{2 \max }$ and LT recorded in the study participant (Table 4) matched those found in elite endurance athletes [19]. However, in this individual case, a marked drop in actual running velocity to $4.13 \mathrm{~km} / \mathrm{h}$ during the subsequent hours, due to the onset of acute chest pain, forced the participant to make the decision to drop out of the race.

The better insight into the metabolic response to exerciseinduced physical strain may be provided by the analysis of changes in biochemical markers (Tables 2 and 3 ). The prerace levels of capillary blood gases, electrolytes and indices of the acid-base balance were within normal ranges, but their marked changes were observed after $12 \mathrm{~h}$ of running. Hyperventilation resulting from sustained running led to hyperventilation-induced hypocapnic alkalosis [20], evidenced by $\mathrm{pH}$ increased by 0.1 units, and marked hypocapnia associated with a $20 \%$ decrease in $\mathrm{pCO}_{2}$. This was accompanied by only minor changes in the plasma electrolyte levels, with no evidence of hyponatremia or hyperkalemia. The stable rest and post- $12 \mathrm{~h}$ running plasma lactate contents support the notion that the mean running speed maintained at this distance $(10.3 \mathrm{~km} / \mathrm{h}) \mathrm{did}$ not exceed the level corresponding to that reached at LT $(12 \mathrm{~km} / \mathrm{h})$ in the incremental running test (Table 2). Moreover, a slightly elevated glucose level recorded after $12 \mathrm{~h}$ of running, though still within the normal range, confirms the presumption of the adequate carbohydrate supply during the race due to providing free access to food to all competitors.

Taking into account that high-level endurance athletes, such as ultra-marathon runners, are at a higher risk of iron deficiency, the symptoms of which can be confused with those of overtraining, the authors evaluated the partici- pant's iron status based on measures of serum iron, serum ferritin, sTfR and the sTfR/ $/ \log _{10}$ ferritin index. In spite of a marked increase in the absolute value of ferritin, a slight increase in sTfR and a marked decrease in serum iron, the levels of the sTfR/ $\log _{10}$ ferritin index were within normal ranges [21] after $12 \mathrm{~h}$ of running, suggesting a normal iron status in the study participant (Table 2). Of note, these findings are in line with those reported by Kasprowicz et al. [22] for middle-aged runners participating in a 100-km ultra-marathon race.

The most important are changes in the hematological and metabolic parameters induced by prolonged strenuous exercise. The pre-race hemoglobin ( $\mathrm{Hb})$ and hematocrit (HCT) levels were not significantly affected following the first $12 \mathrm{~h}$ of the race, but they were significantly reduced during the recovery period. The platelet count (PLT) rose markedly but returned to baseline during the recovery. As expected, finishing a distance of $112.5 \mathrm{~km}$ during $12 \mathrm{~h}$ of the race led to leukocytosis evidenced by a high increase in the white blood cell (WBC) counts with most marked neutrophilia and lymphocytopenia. Similar response to prolonged strenuous exercise (e.g., a classic marathon, or 24-h and 48-h ultra-marathon races) was reported by other authors [10,18,23].

One may presume that this effect is mediated by an increased secretion of cortisol and a reduction of neutrophil degranulation [24]. Marked increases in the serum activities of CK (8-fold) and AST (nearly 2-fold), recorded after $12 \mathrm{~h}$ of running, reflect the extent of the leakage of tissue enzyme proteins into the circulation due to muscle injury arising from myofibrillar disruption [25]. It is well documented that intense long-term physical strain, such as running a marathon, also induces an acute phase of inflammatory reaction, as evidenced by a delayed increase in the hsCRP released from the liver [26], and such a response, continued during the recovery, was recorded in the study participant (Table 3). It is worth to stress that similar significant post-race increases in the levels of 
hsCRP were observed in 7 male amateur runners who successfully completed the same event (i.e., a 48-h ultramarathon race held in the same place) [10].

Another important issue to resolve in this study was to evaluate the impact of the ultra-endurance effort on fat metabolism. The most significant were increases in free fatty acids (7.5-fold) and glycerol (18-fold) observed after finishing the distance covered over a 12-h race, both of which returned to baseline (pre-race) levels following 12-h recovery. This finding, on the one hand, strongly supports the presumption of a substantial mobilization of systemic fat stores during prolonged muscular work and an increased supply of FFA for intramuscular fat oxidation. On the other hand, the elevated levels of free fatty acids may also lead to depression of the inotropic state and an impairment of the heart function [27], as observed in the study participant. As TC, LDL-C, HDL-C and TG were not measured following $12 \mathrm{~h}$ of running, the authors could only comment on their levels assessed following the recovery. The most favorable changes in the lipid profile included a 3-fold decrease in TG and a marked decline in the levels of the atherogenic index of plasma (AIP) [11] providing indirect, but reliable information on the low plasma content of the most atherogenic small dense LDL (sdLDL) particles.

\section{A follow-up history of the athlete's sports achievements}

After dropping out of the ultra-marathon race due to cardiac problems mentioned above, and 2 months spent on regaining his physical and psychological well-being, the athlete resumed his training program. His weekly training plan, which was based on the assumption that the distance covered daily in the outdoor conditions should match his current physical capacity and environmental conditions, is limited to $40 \mathrm{~km}$ daily with 1- or 2-day break over a week to ensure optimal recovery. So, excluding his previous participation in 55 ultra-marathon races, it is worth noting that since 2010 he competed in 11 other ultra-marathon races. He successfully finished 40 marathons held in the period of June 23 - August 3, 2012 in 42 cities in Poland, within the framework of a national project " 42 marathons in 42 days," with an average finishing time of 3.44:43 h. In addition, obviously his most important sports achievements were the completion of 2 extreme running pilgrimages from his home town (Ruda Śląska, Poland) to Vatican, undertaken in 2013 in tribute to Pope John Paul II on the thirty-fifth anniversary of his election, and to Santiago de Compostela in Spain in 2016. During these pilgrimages, he completed the distances of $1590 \mathrm{~km}$ in 24 days (with an average daily distance of $66.3 \mathrm{~km} / \mathrm{d}$ ) and $2973 \mathrm{~km}$ in 43 days (with an average daily distance of $69.1 \mathrm{~km} / \mathrm{d}$ ). The above mentioned athletic achievements support the notion of his high physical performance maintained $>6$ years following his cardiac incident manifested during the 48-h race, and provide strong support for findings from other studies [28] that the chronic accumulation of acute exercise stress may lead to a healthy, physiological adaptation in the heart.

\section{The heart in ultra-marathon running}

It is well-known that participating in an ultra-marathon race leads to immense stress on the athlete's heart [4], inducing changes in cardiac biomarkers in echocardiographic findings [10]. It is also well-known that marathon running can lead to cardiac arrest and death [29]. Ultramarathon running, however, does not seem to increase the risk of cardiac arrest and death since the authors found no case report or field study regarding cardiac death in ultra-marathon running or ultra-endurance performance. This might be due to the fact that ultra-marathon runners compete first in marathons before they change to ultramarathon running [4].

For the development of multiple cardiac abnormalities (e.g., fibrosis, atrial arrhythmias, ventricular arrhythmias, and sudden death), associated with marathon and ultramarathon running, the term "Phidippides cardiomyopa- 
thy" has been proposed [30]. Under these circumstances, repetitive, prolonged elevations of cardiac output, in predisposed individuals, cause a recurrent dilation of cardiac chambers and stimulate resident macrophages, pericytes, and fibroblasts, resulting in the deposition of collagen causing patchy fibrosis. The fibrotic areas, in turn, become the substrate for re-entrant ventricular tachycardia, degeneration to ventricular fibrillation and cardiac abnormality, which are the main cause of sudden death in ultraendurance athletes [16].

Changes to the left ventricle are well-known in ultra-marathon runners [4]. However, also changes to the right ventricle might occur. In contrast to ultra-endurance performance, intense endurance exercise causes acute dysfunction of the right ventricle [31].

\section{Limitations of the case report}

One of the limitations of the study was a lack of data on cardiac biomarkers, such as hsTnT, during and immediately following the drop-out of the race. However, the runner's decision to drop out was based more on predicting his own ability to finish the race with a good result than on the risk of potentially serious cardiovascular complications. Furthermore, a detailed assessment of food and fluid intake during the race did not allow the evaluation of the role of nutrition. In this context, it has been suggested [28] that the mechanism underlying the susceptibility of individual athletes to cardiomyocyte injury stimulated the release of cTnT. This mechanism might be induced by exercises of a strenuous endurance type and might be different from the irreversible cardiomyocyte injury evidenced in acute myocardial infarction. This implied that highly trained athletes might be less, and only temporarily, affected.

\section{CONCLUSIONS}

The physical performance characteristics of the athlete and a follow-up history of his athletic activity showed that the cardiac problems he had experienced during the ultramarathon race did not prevent him from being active in sport. It needs to be noted, however, that as a dynamic systolic narrowing in the eighth segment of the left anterior descending artery, due to a muscle bridge, can be life-threatening. Therefore, cardiologists recommend that individuals with similar cardiac disorders should avoid intense exercise.

\section{ACKNOWLEDGMENTS}

The authors would like to thank Patricia Villiger for her aid in editing the English version of this article.

\section{REFERENCES}

1. Knechtle B, Rüst CA, Rosemann T, Lepers R. Age-related changes in 100-km ultra-marathon running performance. Age. 2012;34(4):1033-45, https://doi.org/10.1007/s11357-011-9290-9.

2. Zingg MA, Rüst CA, Rosemann T, Lepers R, Knechtle B. Runners in their forties dominate ultra-marathons from 50 to 3,100 miles. Clinics. 2014;69(3):203-11, https://doi.org/10. 6061/clinics/2014(03)11.

3. Merghani A, Malhotra A, Sharma S. The u-shaped relationship between exercise and cardiac morbidity. Trends Cardiovasc Med. 2016;26(3):232-40, https://doi.org/10.1016/j.tcm.2015. 06.005 .

4. Knechtle B, Nikolaidis PT. Physiology and pathophysiology in ultra-marathon running. Front Physiol. 2018;9:634, https:// doi.org/10.3389/fphys.2018.00634.

5. Scott JM, Esch BTA, Shave R, Warburton DER, Gaze D, George K. Cardiovascular consequences of completing a 160km ultramarathon. Med Sci Sport Exerc. 2009;41(1):26-34, https://doi.org/10.1249/MSS.0b013e31818313ff.

6. Maron BJ, Pelliccia A. The heart of trained athletes: Cardiacremodeling and the risks of sports, including sudden death. Circulation. 2006;114(15):1633-44, https://doi.org/10.1161/CIRCU LATIONAHA.106.613562.

7. Tan PL, Tan FH, Bosch AN. Assessment of differences in the anthropometric, physiological and training characteristics of 
finishers and non-finishers in a tropical 161-km ultra-marathon. Int J Exerc Sci. 2017;10(3):465-78.

8. Nikolaidis PT, Knechtle C, Ramirez-Campillo R, Vancini RL, Rosemann T, Knechtle B. Training and body composition during preparation for a 48-hour ultra-marathon race: A case study of a master athlete. Int J Environ Res Public Health. 2019;16(6):903, https://doi.org/10.3390/ijerph16060903.

9. Knechtle B, Rosemann T, Nikolaidis PT. Pacing and changes in body composition in $48 \mathrm{~h}$ ultra-endurance running - a case study. Sports (Basel). 2018;6(4):136, https://doi.org/10.3390/ sports6040136.

10. Kłapcińska B, Waśkiewicz Z, Chrapusta SJ, SadowskaKrępa E, Czuba M, Langfort J. Metabolic responses to a 48-h ultra-marathon run in middle-aged male amateur runners. Eur J Appl Physiol. 2013;113(11):2781-93, https://doi.org/ 10.1007/s00421-013-2714-8.

11. Dobiášová M, Frohlich J, Šedová M, Cheung MC, Brown BG. Cholesterol esterification and atherogenic index of plasma correlate with lipoprotein size and findings on coronary angiography. J Lipid Res. 2011;52(3):566-71, https://doi.org/ 10.1194/jlr.P011668.

12. Levy D, Savage DD, Garrison RJ, Anderson KM, Kannel WB, Castelli WP. Echocardiographic criteria for left ventricular hypertrophy: The Framingham heart study. Am J Cardiol. 1987;59(9):956-60.

13. Sales MM, Sousa CV, da Silva Aguiar S, Knechtle B, Nikolaidis PT, Alves PM, et al. An integrative perspective of the anaerobic thresold. Physiol Behav. 2019;205:29-32, https:// doi.org/10.1016/j.physbeh.2017.12.015.

14. Porszasz J, Casaburi R, Somfay A, Woodhouse LJ, Whipp BJ. A treadmill ramp protocol using simultaneous changes in speed and grade. Med Sci Sports Exerc. 2003;35(9):1596-603.

15. Edvardsen E, Hem E, Anderssen SA. End criteria for reaching maximal oxygen uptake must be strict and adjusted to sex and age: A cross-sectional study. PLoS One. 2014;9(1):e85276, https://doi.org/10.1371/journal.pone.0085276.

16. O'Keefe JH, Pati, HR, Lavie CJ, Magalski A, Vogel RA, McCullough PA. Potential adverse cardiovascular effects from excessive endurance exercise. Mayo Clin Proc. 2012;87(6): 587-95, https://doi.org/10.1016/j.mayocp.2012.04.005.

17. Guasch E, Mont L, Sitges M. Mechanisms of atrial fibrillation in athletes: What we know and what we do not know. Neth Heart J. 2018;26(3):133-45, https://doi.org/10.1007/ s12471-018-1080-x.

18. Waśkiewicz Z, Kłapcińska B, Sadowska-Krępa E, Czuba M, Kempa K, Kimsa E, et al. Acute metabolic responses to a 24-h ultra-marathon race in male amateur runners. Eur J Appl Physiol. 2012;112(5):1679-88, https://doi.org/10.1007/ s00421-011-2135-5.

19. Joyner MJ, Coyle EF. Endurance exercise performance: The physiology of champions. J Physiol. 2008;586(Pt 1):35-44, https://doi.org/10.1113/jphysiol.2007.143834.

20. Chin LMK, Heigenhauser GJF, Paterson DH, Kowalchuk JM. Pulmonary $\mathrm{O} 2$ uptake and leg blood flow kinetics during moderate exercise are slowed by hyperventilation-induced hypocapnic alkalosis. J Appl Physiol (1985). 2010;108(6):1641-50, https://doi.org/10.1152/japplphysiol.01346.2009.

21. Suominen P, Punnonen K, Rajamäki A, Irjala K. Serum transferrin receptor and transferrin receptor-ferritin index identify healthy subjects with subclinical iron deficits. Blood. 1998;92(8):2934-9.

22. Kasprowicz K, Ziemann E, Ratkowski W, Laskowski R, Kaczor JJ, Dadci R, et al. Running a 100-km ultra-marathon induces an inflammatory response but does not raise the level of the plasma iron-regulatory protein hepcidin. J Sports Med Phys Fitness. 2013;53(5):533-7.

23. Jastrzębski Z, Żychowska M, Jastrzębska M, Prusik K, Prusik K, Kortas J, et al. Changes in blood morphology and chosen biochemical parameters in ultra-marathon runners during a $100-\mathrm{km}$ run in relation to the age and speed of runners. Int J Occup Med Environ Health. 2016;29(5):801-14, https://doi.org/10.13075/ijomeh.1896.00610.

24. Robson PJ, Blannin AK, Walsh NP, Castell LM, Gleeson M. Effects of exercise intensity, duration and recovery on in vitro neutrophil function in male athletes. Int J Sports Med. 1999;20(2):128-35. 
25. Kim HJ, Lee YH, Kim CK. Biomarkers of muscle and cartilage damage and inflammation during a $200 \mathrm{~km}$ run. Eur J Appl Physiol. 2007;99(4):443-7.

26. Petersen AMW, Pedersen BK. The anti-inflammatory effect of exercise. J Appl Physiol (1985). 2005;98(4):1154-62.

27. Seals DR, Rogers MA, Hagberg JM, Yamamoto C, Cryer PE, Ehsani A. Left ventricular dysfunction after prolonged strenuous exercise in healthy subjects. Am J Cardiol. 1988;61(11):8759, https://doi.org/10.1016/0002-9149(88)90362-1.

28. Whyte G, Stephens N, Senior R, George K, Shave R, Wilson M, et al. Treat the patient not the blood test: The implications of an increase in cardiac troponin after prolonged endurance exercise. Br J Sports Med. 2007;41(9):613-5, https://doi.org/10.1136/bjsm.2006.033720.
29. Webner D, Duprey KM, Drezner JA, Cronholm P, Roberts WO. Sudden cardiac arrest and death in united states marathons. Med Sci Sports Exerc. 2012;44(10):1843-5, https://doi.org/10.1249/MSS.0b013e318258b59a.

30. Trivax JE, McCullough PA. Phidippides cardiomyopathy: A review and case illustration. Clin Cardiol. 2012;35(2):6973, https://doi.org/10.1002/clc.20994.

31. La Gerche A, Burns AT, Mooney DJ, Inder WJ, Taylor AJ, Bogaert J, et al. Exercise-induced right ventricular dysfunction and structural remodelling in endurance athletes. Eur Heart J. 2012;33(8):998-1006, https://doi.org/10.1093/eurheartj/ehr397.

This work is available in Open Access model and licensed under a Creative Commons Attribution-NonCommercial 3.0 Poland License - http://creativecommons.org/ licenses/by-nc/3.0/pl/deed.en. 